\title{
RETÓRICAS DEL MEME MASCULINISTA. UNIVERSIDAD DIGITAL Y ANTIFEMINISMO EN TIEMPOS DE PANDEMIA
}

\author{
Masculinism Meme Rhetorics. Digital University and Anti-Feminism \\ on Pandemic Times
}

MAURICIO ZABALgoITIA HERRERA

IISUE-UNAM (MÉXICO)

MAURICIO.ZABALGOITIA@GMAIL.COM

ORCID: 0000-0003-0806-0887

DOI: https://doi.org/10.5565/rev/mitologias.834

vol. 25 | enero 2022 | 68-90

Recibido: 15/10/2021 | Aceptado: 15/12/2021

Resumen:

En este trabajo se parte del repunte y visibilización de violencias sexistas por motivo de la pandemia por la COVID-19 en México. En esta línea, se apunta al confinamiento de las relaciones, planteándose una universidad digital en cuyas interacciones crecen expresiones de ciberviolencia y antifeminismo. Este escenario es confrontado con el orden de género vigente, referido al reciente activismo de jóvenes feministas y a los debates producto de la discusión sobre masculinidades, apuntándose a nuevas subjetividades dentro de un extremo masculinista. Con esto, se teoriza una aceleración de tal radicalismo, mirando a cuestiones como la "manosfera", la replicación de sus afectos en interacciones digitales de estudiantes universitarios, y al ejercicio de una tropología basada en la comunicación mediante memes, la cual conforma una particular retórica. Finalmente, se analizan memes publicados por estudiantes en grupos dentro de esta esfera y en el ámbito pandémico.

Palabras clave:

Pandemia, universidad digital, ciberviolencia, antifeminismo, masculinismo, meme 


\section{Abstract:}

This work begins with the rise and visibility of sexist violence due to the COVID-19 pandemic in Mexico. In this context, it focuses on the study of relationships during confinement, proposing that cyber violence and anti-feminism grow in a digital university. This scenario is confronted with the current gender order, referring to the recent activism of young feminists and to the debates resulting from the discussion on masculinities, pointing to new subjectivities within a masculinist extreme. With this, an acceleration of such radicalism is theorized, looking at issues such as the "manosphere", the replication of their affects in digital interactions of university students, and the exercise of a tropology based on communication through memes, which forms particular rhetoric. Finally, memes posted by students in groups within this sphere and in the pandemic are analyzed.

\section{Keywords:}

Pandemics, Digital University, Cyberviolence, Antifeminism, Masculinism, Meme 


\section{Pandemia, violencias sexistas y universidad digital}

Tras algo más de año y medio de pandemia por la COVID-19, así como de un prolongado confinamiento y la permanencia de las actividades a distancia, desde perspectivas críticas de género en México se hicieron visibles violencias y desigualdades al interior de los hogares, sobre todo apuntándose a la situación de mujeres, niñas y niños. A este respecto, se habló de jornadas dobles y triples, de una intensidad en la división sexual de tareas o de un retorno a las viejas mitologías de cuidados y la natural predisposición para educar por parte de las mujeres (López, 2020: 75). Asimismo, las lecturas feministas denunciaron un peligroso repunte de violencias sexistas, las cuales se multiplicaron al coincidir las familias en los hogares y compartir los recursos (Alcocer, 2020; Galván, 2020; Heath y Rayasam, 2020). Además, desde miradas sensibles a las desigualdades en términos de género, se hizo patente cómo es que a las lógicas basadas en la diferencia entre mujeres y hombres se suma, en momentos límite como este, un desigual acceso a la salud, a las viviendas en condiciones y al home office. En la línea de estas lecturas, si bien se apela directamente al lugar que los hombres ocupan en la suma de excepcionalidad, sexismo y violencia, habría que reparar en una aparente exacerbación de viejas posiciones subjetivas de masculinidad que en las interacciones del mundo digital se han visto particularmente aceleradas.

Mirando a la experiencia universitaria, se piensa que las condiciones de acceso a los medios de conexión visibilizaron formas bajo las que las subjetividades masculinas continúan estando mucho mejor situadas a la hora de proteger sus tiempos y medios de trabajo. Las jóvenes, como en la mayoría de los lugares de la vida social, resultaron más expuestas a violencias cotidianas, simbólicas y físicas, destacándose aquellas con carácter sexual que se producen en el extremo de la vida digital. En esta vida inédita, expresiones variadas de ciberviolencia ${ }^{1}$ se vieron dinamizadas, de acuerdo con formas de interacción que, en el caso de las, los y les estudiantes universitarios, constituyeron la única vía de acceso a los sentidos de la vida social y cultural que se construyen en los espacios y relaciones no formales de la experiencia educativa. Estas formas de violencia simbólica no son nuevas, pero como siempre que se observan con la mirada crítica que opera desde el género conforman una suerte de escala ${ }^{2}$ que va desde expresiones machistas, aparentemente inofensivas, solapadas bajo el humor o la cultura popular, a formas elaboradas, organizadas y explícitas de violencia cotidiana.

El estudio específico de manifestaciones de violencia de género en interacciones digitales y a través de tecnologías de la información se ha venido estudiando en el ámbito mexicano, destacándose el año 2016, mismo que coincide con iniciativas de activismo digital como \#MiPrimerAcoso. ${ }^{3}$ De este modo, mientras las mujeres toman las redes para denunciar los diversos modos en los que son acosadas desde niñas, algunos trabajos destacan lo que sucede "en línea" y que las afecta a ellas, como en el resto de ámbitos, de manera desproporcionada. Estefanía Vela y Erika Smith (2016) redefinen el contexto de la violencia de género para puntualizar formas muy claras en ámbitos de uso de la información y la tecnología, como lo son: a. difusión, sin el consentimiento de la víctima, de datos e imágenes personales, destacándose fotos o videos en los que aparecen desnudas o realizando algún acto sexual: b. amenazas,

\footnotetext{
1 "La ciberviolencia es ser cruel con alguien aprovechando la conectividad, se trata de cualquier forma de hostigamiento, intimidación u hostilidad a través de las TIC. [S] e caracteriza por la posibilidad de presentarse en cualquier momento y espacio, los 365 días del año, pues se beneficia de la movilidad y conectividad de los dispositivos electrónicos, lo cual, facilita el almacenaje y distribución a una potencial mayor audiencia" (Velázquez, 2021: 3).

2 Araceli Mingo y Hortensia Moreno trazan una "escala de sexismo", mirando a las universidades, en las que se miden desde expresiones simbólicas hasta formas de acoso o amenazas de muerte (2015: 141). Se propone que en la retórica de los memes masculinistas esta escala se replica.

${ }^{3}$ Se trata de una iniciativa de activismo digital que consistió en una réplica de un hilo de conversación en Twitter, por parte de la feminista brasileña Juliana de Faria. En México, desde la cuenta “(es)tereotipas” (Vela y Ruiz-Navarro) se lanzó el hashtag \#MiPrimerAcoso, invitando a mujeres a compartir sus testimonios. Se destaca la amplia variedad e incidencia de las expresiones de este tipo que sufren mujeres de ámbitos diversos, así como el debate que se abre en cuanto a nociones como pedofilia, niñez, familia y cuidados (Ruiz-Navarro, 2016).
} 
las cuales incluyen mecanismos de acoso y hostigamiento, y que suelen conllevar formas de extorsión; c. difamación y daño de la imagen, mediante acusaciones públicas y falsas; d. acechamiento y monitoreo bajo el pretexto de establecer una relación, aún cuando la víctima la ha rechazado; d. acoso específico mediante imágenes, correos y comentarios, por ejemplo con contenido sexual no solicitado; e. formas de violencia diversas, como el ataque organizado a páginas colectivas o personales de feministas, acceso ilegal a cuentas y perfiles, etc. ${ }^{4}$

La ciberviolencia, con esto, materializada en dispositivos específicos — sobre todo en redes sociodigitales-, y cuya finalidad es el mantenimiento de un orden masculino, en las interacciones pandémicas parece haber tenido un momento de gran fertilidad para verse multiplicada. Por un lado, se retoman los viejos recursos del sexismo cotidiano, como las prácticas de hostigamiento y acoso; además, formas de una aparente "baja intensidad" se replican como constantes que, en muchas ocasiones, hacen de la vida social digital espacios amenazantes y hasta "fríos", ${ }^{5}$ de acuerdo con la comprobación de que el uso cotidiano de chistes, ejemplos y expresiones sexistas actúa como amenaza —o promesa— de violencia sexual hacia mujeres, hombres menos hombres y otras identidades sexogenéricas.

Como han señalado estudios y notas periodísticas, durante el confinamiento aumentó el ciberacoso ${ }^{6}$ en México, sobre todo porque las clases en línea incrementaron el flujo de personas jóvenes en la red, replicándose la vida educativa no solo en lo formal, pues llevar las aulas físicas a las virtuales aumentó el uso de las tecnologías como instancias de socialización (Toche, 2020: s/p). Si ya antes de la pandemia, de acuerdo con la ENDUTIH, ${ }^{7}$ dentro de la población de 12 a 59 años que usa internet el $16.8 \%$ había experimentado alguna situación de acoso virtual, destacándose el sufrido por las mujeres jóvenes, algunos indicadores señalan un alto incremento entre 2019 y 2020, según El Consejo para Prevenir y Eliminar la Discriminación de la Ciudad de México (COPRED, 2020: 42).

Este trabajo parte, con esto, de la propuesta de que con el confinamiento de las experiencias formales e informales universitarias, así como con la suspensión de la vida social offline, a lo largo del 2020 y en la primera mitad del 2021, en lugares como México se genera un claro aumento de sentimientos y manifestaciones antifeministas. Estos, a su vez, provocan una intensificación de formas de violencia digital bajo manifestaciones de sexismo, provenientes de un espacio inédito — la manosfera ${ }^{8} \mathrm{y}$ mediante la problematización de una visión de mundo masculinista. ${ }^{9}$

Como marco para explicar esta posibilidad se observa una universidad digital que replica las formas esenciales bajo las que la masculinidad opera de manera tradicional. Por ejemplo, mediante ideales materializados cada vez más en figuras de la esfera online, por medio de aplicaciones como Instagram o

\footnotetext{
${ }^{4}$ Para dimensionar los mecanismos, causas y efectos de estas expresiones de violencia de género y sexual, así como las formas bajo las que reproducen estereotipos de la diferencia sexual, consultar el trabajo completo: Vela y Smith (2016).

${ }^{5}$ El acoso y hostigamiento conforman "climas fríos" (Mingo y Moreno, 2017: 574), sobre todo para las mujeres, a través de su repetición y sistematización en los espacios de la educación. Ahí ellas se sienten constantemente incómodas y amenazadas. ${ }^{6}$ Del inglés cyberbullying.

${ }^{7}$ Encuesta Nacional sobre Disponibilidad y Uso de las TIC en Hogares (en Toche, 2020: s/p).

${ }^{8}$ Del inglés manosphere, como término aparece por primera vez en 2009 en la blogosfera para describir a una red de hombres con el interés de crear comunidad y discutir su situación. El término fue rápidamente adoptado por activistas de los derechos de los hombres (MRA), como Ian Ironwood, autor de The Manosphere: a New Hope for Masculinity (2013). La noción recibió atención mediática por su "misoginia extrema" (Ging, 2019: 639-640).

${ }^{9} \mathrm{El}$ masculinismo, definido como un "movimiento que busca igualdad entre el hombre y la mujer, desde la perspectiva del varón” (Ferrero, 2017: s/p), agrupa posiciones, manifestaciones, intenciones y quejas antifeministas. En buena parte, el masculinismo presupone la superioridad del hombre, así como la necesidad de excluir a las mujeres y a sus movimientos de liberación, además de promover un retorno a su dominio. Tiene raíces dispersas y variadas, la cuales incluyen fuentes antiguas, expresiones políticas modernas y al movimiento mitopoético. Entre sus temas centrales se encuentra la desaventajada posición de los hombres frente al ascenso de las mujeres en la educación, el empleo, el hogar y la paternidad. Entre otras cuestiones, niegan la violencia de género, sobre todo argumentando que ellos también la sufren. Forman parte de la manosfera.
} 
TikTok, como son youtubers, influencers, cantantes de reguetón o futbolistas. Asimismo, a través de estrategias con las que se aseguran la permanencia en lugares privilegiados o en aquellos bajo los que siguen obteniendo dividendos, por ejemplo replicando o guardando silencio ante las expresiones de violencia sexista — ahora en el extremo ciber-. Finalmente, y de forma destacada, también generando y promoviendo subculturas homosociales masculinas en las que se cuestiona, resiste y confronta el ascenso de los feminismos y su rica cultura expresiva mediante el ciberactivismo.

Lo anterior parte de reflexiones y miradas que se centran en la recurrencia a viejos debates, lo que asienta conocidas posiciones de subjetividad masculina, pero a su vez genera nuevas y convenientes formas de masculinidad; una remarcada aceleración de posiciones machistas y retrógradas, lo que dinamiza el camino de algunos estudiantes hacia el masculinismo — calcado de una esfera intemaciona—, además de etiquetas para dar nombre a los inconformes; el perfeccionamiento de una eficaz comunicación basada en memes — dispositivos textuales situados en la cima de la comunicación actual; y el recurso a viejas y nuevas retóricas —-mediante una tropología ${ }^{10}$ que replantea al sexismo—, trazándose, así, otra cara de la pandemia: la de una universidad digital sexista que promueve la reorganización de varones mediante el uso de estrategias puntuales de ciberviolencia, así como de un creciente contra activismo masculinista.

Esto lleva a preguntar, de manera inicial, ¿con qué orden de género impacta la pandemia en México y en las universidades? ¿Y frente a qué tensiones de subjetividad se topa para replicar y amplificar lógicas de dominio y exclusión bajo prácticas de subjetividad masculinas?

\section{Masculinidades y orden de género vigente. Viejos debates, mismas posiciones}

El campo de estudio de las masculinidades identifica desde sus inicios polarizaciones en cuanto a la respuesta de los varones no solo frente al ascenso de los feminismos, así como de sus señalamientos y demandas en espacios claramente jerarquizados y desiguales, como la universidad, sino frente a la propia construcción e instauración de estos estudios en diversas disciplinas sociales y humanísticas. Olivia Tena describe dos lugares en un extremo positivo, los grupos de "hombres por la igualdad" y los varones "profeministas". En el otro, ubica a los hombres que identifican al feminismo como una clara amenaza, presentando, así, a la masculinidad como un bien "en peligro"; como un sistema "en crisis" (2010: 273-274).

De acuerdo con Debbie Ging, en un trabajo acerca de las formas de masculinidad que en el ahora conforman la llamada "manosfera", se observa una continuidad de base que enlaza a las subjetividades de hace décadas con las de hoy. En formas que cambian, sobre todo en cuanto a soportes y modos de interacción, los antifeministas mantienen un lenguaje conservador acerca de los roles de género, mientras que los varones que miran al profeminismo en general continúan adoptando un discurso abierto sobre las relaciones, con la meta de erradicar los privilegios y la violencia en contra de las mujeres (Ging, 2019: 639). Un objetivo, este último, que se replica tanto en los ámbitos académicos como de activismo social, pero que no suele materializarse, y mucho menos ha constituido una agenda clara y explícita como en los movimientos feministas.

\footnotetext{
${ }^{10}$ La tropología posee un significado inicial al referir al "lenguaje figurado", el cual se expresa mediante tropos. El tropo es, así, una figura retórica de sustitución; un desvío, un juego, en donde el sentido original desemboca en uno nuevo. Ahora, desde la filosofía y la historia, la tropología apunta al estudio de los modos organizados sobre los que opera un discurso determinado — por ejemplo, de género-. A estos se suma un tercero: "Mezcla de moralidad y doctrina en el discurso u oración, aunque sea en materia profana o indiferente" (RAE: s/p). Lo que aquí se denomina "tropología masculinista" mira a las tres posibilidades.
} 
En la actualidad, estas posiciones se mantienen, a pesar del auge que los estudios de los hombres y de la masculinidad han venido teniendo, sobre todo como resultado de dos ejes cuya confluencia ha cuestionado a todos los espacios de la vida y a las universidades de manera destacada. El primero es el de años de políticas de transversalización de género en las instituciones de educación superior (IES) (Buquet, 2011). El otro se conforma desde los señalamientos, peticiones y emociones, como la rabia o el cansancio (Cerva, 2020) que emanan del reciente movimiento de mujeres jóvenes y estudiantes, el cual se materializa en formas inéditas de activismo y protesta frente al temor y el desprecio que surgen desde el sexismo en la universidad (Mingo y Moreno, 2019).

Desde 2014 comienzan a surgir más grupos de colectivas feministas en las universidades mexicanas. Este activismo se conecta globalmente, en gran medida de acuerdo con la aceleración del ciberactivismo y la ocupación, por parte de las mujeres, de los espacios de la comunicación digital con carácter continental y transatlántico. Desde diversas latitudes, se señalan y confrontan las violencias cotidianas en aulas, pasillos y otros lugares de la universidad, así como las prácticas regulares de hostigamiento y acoso sexuales. Este clima dinámico y novedoso se materializa a través de movimientos como "Ni una Menos" o "Vivas nos queremos", promoviendo estrategias de denuncia alternativas bajo el \#MeToo y a partir de performances con incidencia mundial como "El violador eres tú” (2019) (Mingo, 2020). ${ }^{11}$

El activismo feminista, con un pie en las instituciones y otro en "las redes", durante el confinamiento encontró en la vida digital los medios para subsistir, reforzando estrategias, por ejemplo, de visibilización de formas específicas de violencia, como son aquellas que acontecen en las aulas virtuales mediante plataformas como Zoom. Estas acciones permitieron evidenciar prácticas que antes permanecían bajo los muros del salón de clases. En 2020, dos casos de violencia verbal sexista fueron dados a conocer mediante el ciberactivismo, los dos proferidos por docentes varones de licenciaturas de la UNAM, ${ }^{12}$ mediante la grabación de dichas clases. En uno de estos, el profesor le dice a una alumna que para obtener una mejor nota no sabe muy bien qué debería ofrecerle, pues sexo no se puede puesto que se está en pandemia (Unotv, 2020: s/p). En el otro, el docente utiliza el espacio de la clase para compartir una vieja tradición, la de clasificar a las compañeras del aula mediante recursos de sexualización y degradación. Con esto, habla de que en su época había una "niña" a la que llamaban "la mufla de oro", pues era la más ardiente. A otra, en cambio, se le refería como aquella "niña que con unos golpes aflojaba, como las bolsas de hielo". Dentro de tal performance masculino, termina por preguntar a los varones ellos cómo le hacen para aflojar a las bolsas de hielo (Unotv, 2020: s/p); esto es, a sus compañeras en la universidad. En ambos casos los profesores fueron retirados de las asignaturas.

Este tipo de actividades de denuncia se suma a una replicación digital de las estrategias físicas de exhibición, como los tendederos, en páginas y grupos de Facebook como "MeToo Filosofía y Letras". En estos espacios se muestran fotos de estudiantes y docentes, regularmente acompañadas de testimonios sobre hostigamiento, acoso, abuso y algunas formas de extorsión — como la obtención de imágenes mediante amenaza-, acometidas mediante recursos de violencia signados por las interacciones en la esfera digital.

En un ámbito transnacional e hiperglobalizado, Ging identifica tres cambios que inciden en las relaciones digitales y de género recientes, a partir de los cuales se reconfiguran las subjetividades de masculinidad en el extremo negativo: la institucionalización y profesionalización del feminismo, la emergencia generalizada de una sensibilidad cultural postfeminista y el desarrollo de la economía neoliberal (2019: 639). Es decir, si antes de la pandemia los significantes y métodos para hacer palpables

\footnotetext{
11 En México, este ambiente de acción política emergente se ve dinamizado por algunos hechos terribles, como los feminicidios, en 2017, de Lesvy Berlín en la UNAM y de la estudiante Mara Fernanda Castillo en Puebla, secuestrada, violada y asesinada por un conductor de Cabify. En la UNAM, de forma específica, estos hechos se suman a casos de violencia sexista no solo puntuales, sino de figuras de abusadores de larga tradición.

12 Universidad Nacional Autónoma de México.
} 
una variedad de formas de sexismo se daban tanto en la esfera universitaria como en las ciberinteracciones, con el confinamiento estas últimas se dinamizan, en gran parte como reacción al ciberfeminismo.

Una vez más, en el extremo positivo algunos hombres se reafirman en la igualdad; y muchos de estos, incluso avanzan abiertamente hacia el profeminismo. Aquí se unen la reflexión académica con las asociaciones civiles que miran tanto a formas de activismo y a la investigación como a estrategias con el "trabajo con hombres". ${ }^{13}$ De acuerdo con la línea que venimos trazando, el trabajo con hombres desde esta perspectiva apunta a la masculinidad como un constructo directamente relacionado con las violencias - y con la violencia de género en particular-, pero que puede ser redirigido, mediante la formación y la consciencia, hacia formas alternas de masculinidad. El profeminismo, por su parte, aparentemente situado en el mismo polo, es mucho más complejo, menos claro; se resiste a la definición. Jokin Azpiazu (2017) apunta a la problemática de la cabida de los hombres en la deriva de los feminismos, no ya solo desde los límites que establecen las posiciones éticas y teóricas - ¿puede un sujeto encarnado en la masculinidad ser feminista? - , sino desde algunas lecturas y reflexiones que, de hecho, miran al profeminismo desde una amplia zona llena de matices.

Más allá de estos lugares de expresión, dicha zona de grises conforma un espacio digital complejo, cargado de tensiones. Michael Messner (2016) las resume bajo la confluencia de diversas fuerzas. En primer lugar, el hecho de que en un tiempo postfeminista se dé por sentado el discurso de la igualdad de género. De ahí que para el sociólogo la subjetividad más peligrosa en las masculinidades recientes sea aquella que habla desde una variedad aparentemente más "amable y gentil". Esta la constituyen varones que practican una estrategia de derechos de los hombres moderada, neoliberal y profesionalmente institucionalizada, que elude el análisis de las desigualdades estructurales en favor de un sentido común que celebra, en apariencia, la igualdad (Ging, 2019: 639). Lejos de los temas de los hombres abogando que ellos también sufren violencia doméstica, que las leyes fallan en su contra a la hora de solicitar la custodia de sus hijos/as, que el divorcio los sitúa en posición de desventaja o que la educación se ha feminizado tanto que los varones ya no tienen cabida (Ging, 2019: 639), estas posiciones menos chocantes se mueven entre la sospecha y la indiferencia, pero con la intención de no renovar lo suficiente a los órdenes de género para no modificar los privilegios y dividendos patriarcales.

El problema con estas subjetividades surge, precisamente como Messner lo señala, en la vida digital, ahí en donde las posiciones antifeministas alcanzan una virulencia mucho más alta, haciéndose necesaria una vista crítica particular a estos espacios (Ging, 2019: 639). Esto lo señala antes de la pandemia. Ahí se reproducen con enorme efectividad posiciones que desde "las redes" apuntan a un claro "declive de los hombres". Para el autor, esta combinatoria ha venido acelerando el resurgimiento de posiciones ligadas al movimiento por los derechos de los hombres ${ }^{14}$ (Ging, 2019: 639), que en la educación superior va acompañado de ideas como la de una "batalla de los sexos" perdida por los varones y la certeza de que ellos estarían teniendo muchas menos oportunidades y apoyo en la experiencia universitaria (Haywood y Mac an Ghaill, 2013). Es desde estos vectores que algunos hombres marcados por temas de género estarían realizando el camino contrario, retomando viejos tropos misóginos y sexistas, y configurando nuevos y organizados modos bajo un complejo subjetivo ahora elevado en la vida digital en pandemia; el mencionado masculinismo.

El extremo masculinista parece convocar con cierta habilidad tanto a quienes sospechan, se incomodan e intentan evitar al feminismo, como a aquellos a los que claramente el mundo presente les genera un problema y las mujeres un claro enemigo a vencer. La suma de pandemia y tensiones en la

\footnotetext{
${ }^{13}$ Como ejemplo, entre otras, en México destaca GENDES (Género y Desarrollo A.C.) como espacio desde el que se mira a la igualdad de género promoviendo labores de atención a hombres, de prevención de la violencia, de formación, así como el diseño de políticas públicas, la difusión en estudios de la masculinidad y consultoría.

${ }^{14}$ Grupos organizados de hombres que luchan en contra de la discriminación en lo legal, lo laboral, así como frente a lo que consideran falsas acusaciones de violencia de género y un extremo avance del feminismo, el cual los minimiza y confronta.
} 
práctica subjetiva de masculinidades permite retomar estas posiciones, fomentando recursos discursivos bajo la enorme eficacia replicativa de dispositivos de comunicación digital como el meme.

\section{Aceleración masculinista en tiempos de la universidad digital}

Ging identifica un problema clave en el desarrollo de las violentas interacciones sexistas en tiempos digitales, no solo porque revelan pruebas para pensar que el movimiento de los derechos de los hombres se está fortaleciendo, sino porque esas mismas evidencias demuestran que hay límites que se están cruzando hacia la radicalización (2019: 639). Con esto, el sexismo online mantiene muchas de las conocidas posiciones y estrategias, aunque no todas. Como nicho de la masculinidad, en formas diversas se adapta a los tiempos, por ejemplo, suavizando algunas de las condiciones clásicas, como la homofobia, pero reforzando, mediante creativas estrategias, aquellas que implican la asociación entre pares masculinos como condición esencial para que la masculinidad opere como lugar subjetivo para resistir a la amenaza feminista. Así, se mantienen por lo menos dos de sus esencias: la siempre presente y amplificada manifestación de terror a lo femenino y la condición de base que la masculinidad exige para funcionar: la homosociabilidad.

Como movimiento amplio y transnacional que recluta a subjetividades muy variadas, acelerado exponencialmente por la orilla digital a la que la vida universitaria es llevada, el masculinismo opera mediante diversas formas. Algunas de estas son abiertamente agresivas y se ubican en ámbitos como el de la cibermisoginia o el ciberacoso. Otras, en cambio, se amparan bajo discursos legalizados por el mercado editorial y espacios de difusión aparentemente académicos, o por unas reglas de comunicación digital políticamente correctas, según redes como Facebook. Entre las particularidades de esta nueva fase de las asociaciones contrafeministas destaca la unión de posiciones subjetivas que en un tiempo pre pandemia resultarían antagónicas. En la manosfera adaptada a la vida confinada, universitarios de diferentes lugares, instituciones, procedencias y variantes de clase, e incluso de género y sexualidad, configuran una suerte de nueva agenda misógina. Esto puede percibirse en grupos como "Masculinismo México" "15 en Facebook.

Entre las estrategias con las que se traza la agenda del masculinismo destacan: a. convertir el movimiento por los derechos de los hombres en "activismo" (Ging, 2019: 640). Esto les ha permitido redes de conexión entre organizaciones, blogs, fórums, comunidades y subculturas, borrándose, como se ha dicho, barreras ideológicas antes insalvables (Nagle, 2015); b. la configuración de un mundo paralelo, virtual y transnacional - la manosfera-, que permite operar desde vectores propios. Esto porque, como lo demuestran algunos de los lugares comunes de base, para ellos el feminismo ha adquirido la forma de una ley que les reduce y afecta; c. la construcción de narrativas, aparentemente sencillas, pero efectivas en su replicación y capacidad para agrupar a esas formas de masculinidad tan diversas.

Entre tales ficciones, resaltan aquellas provenientes de una cultura popular transnacional. Una es la Red Phill philosohy. Es decir, una lectura sesgada de la película The Matrix (1999), ${ }^{16}$ en la que a Neo,

\footnotetext{
15 "Masculinismo México es un proyecto surgido de la mano de jóvenes universitarios de diferentes partes de la República Mexicana, interesados en difundir las causas de Los Movimientos por los Derechos de los Hombres (Men Rights Movement) que han tomado fuerza las últimas décadas en países como Inglaterra, EUA y la India" (Masculinismo México: s/p). En su descripción principal se menciona: "Espacio virtual Masculinista/MRA dedicado a difundir los problemas e injusticias que sufre el hombre en México y el mundo. Además de reflexiones y críticas de ideas provenientes de la Androsfera y el feminismo" (Masculinismo México: s/p).

${ }^{16}$ Otra película del mismo año resulta especialmente influyente en la configuración mítica de la manoesfera, esta es The Fight Club (1999). De acuerdo con la recepción y crítica, se puntualizó cómo a pesar de tocar algunas de las fibras de la "crisis de la masculinidad", una mala lectura podría derivar en la celebración de la violencia con tintes misóginos. A lo largo de EUA se replicaron "clubes de lucha" como espacios de liberación masculina.
} 
el protagonista, se le ofrece la posibilidad de escoger entre dos pastillas. Una es la azul, que lo llevaría a permanecer en un mundo de engaño e ilusiones. La segunda, la roja, por el contrario lo liberará y le mostrará la terrible verdad de la vida (Ging, 2019: 640). La analogía es en extremo simple, transparente. Los hombres que se decidan por esta última opción abrirán los ojos ante el odio y la misandria que promueve el feminismo, así como del lavado de cerebro que significa para muchos (Ging, 2019: 640).

La transparencia de esta retórica es un ejemplo destacado, sin embargo, de cómo es que el masculinismo promueve expresiones de discursiviad de gran éxito y penetración. Con la metáfora de la Matrix lo que está haciendo es convertir a un movimiento de liberación y cambio, el feminismo, en una ideología peligrosa — como se argumenta en el posterior análisis de los memes-. Esta suerte de recursos, sobre todo retóricos, en el mundo virtual y de ética difusa, la internet, al ampararse, por ejemplo bajo la neoliberal promesa de una libertad de expresión total, exigen a sus miembros la evidencia de ciertos principios, como el de un renovado sexismo. La diferencia radica en que en el mundo universitario real este permanecería solapado bajo gestos y expresiones simbólicas y cotidianas. En la esfera masculinista, en cambio, se materializa en formas muy claras; explícitas.

\section{¿Nuevos sujetos? Masculinismo virtual y estudiantil en México}

En este ámbito transnacional, hiperglobalizado y confinado, Judith Butler piensa que la lógica del virus depende completamente de la modelización que sufrimos por los poderes entrecruzados de género, racismo, nacionalismo y xenofobia (2020: 62). Paul B. Preciado, por su parte, durante el primer semestre de la pandemia, reflexionó en cuanto a una acelerada descorporeización por los nuevos límites y fronteras (tanto reales como digitales), así como por las exigencias de un capitalismo neoliberal cada vez más interesado en romper los núcleos comunitarios. Para el filósofo, las nuevas subjetividades abandonan huesos, carne y piel; no tienen labios ni lenguas, ya que no practican las interacciones cara a cara. Viven bajo las máscaras de mediaciones semio-técnicas y mediante prótesis cibernéticas: el correo electrónico y los perfiles de Facebook e Instagram (2020: 178). Es en este contexto pandémico que se pueden situar algunas de las formas de masculinidad que orbitan alrededor del masculinismo.

Según una jerarquía, en primer lugar podemos encontrar a los autodenominados betafags. De acuerdo con Angela Nagle, se trata de un hombre no excesivamente masculino, incluso débil de acuerdo con los valores tradicionales. Pero esta etiqueta también es una marca de identidad bajo la que se autoconstruyen varones pertenecientes a cierta cultura digital, regularmente mediante avatares, partiendo de la idea de que no están a la altura de los ideales de la masculinidad vigente, así como de las expectativas sociales ligada a esta. De este modo, se presentan como geeks, ${ }^{17}$ incels $^{18}$ y antisociales (2005: 110).

Ging muestra cómo estos sujetos se autodenominan "social justice warriors", por ejemplo organizando campañas de venganza contra las mujeres, pero también contra los hombres alpha, que son quienes les privan del éxito sexual (2019: 640). Michael Kimmel agrega un llamado a la victimización y al derecho agraviado, en tanto hombres jóvenes y blancos que se consideran privados de sus derechos (2015: 35). La convergencia de una diversidad de sentimientos y expresiones alrededor de estas ideas, en donde no solo varones blancos interactúan, sino, de hecho, bajo algunas normas relajadas, participan sujetos homosexuales, negros, latinos y otros tantos pertenecientes a categorías no privilegiadas por la lógica occidental, permite hablar de un "beta uprising" y de la "masculinidad beta". Tal levantamiento -

\footnotetext{
${ }^{17}$ En un inicio refiere a un hombre que vive mediante la tecnología y la informática; y desde ahí desarrolla sus gustos y relaciones sociales. Desde un punto de vista crítico de masculinidades, se suma la incorporación de algunas de las características de las llamadas masculinidad tóxica o hegemónica.

${ }^{18}$ Célibes involuntarios por motivo del orden de género vigente. Las mujeres los segregan por no dar la talla en cuanto a los ideales del hombre exitoso. Promueven un sexismo violento.
} 
o despertar-, y la posibilidad de habitar una masculinidad distinguida como propia inciden directamente en la configuración de la manosfera.

En este ámbito, la masculinidad tóxica, que desde frentes teóricos y de activismo feminista ha servido para señalar los ideales reprobables en el orden de género vigente, desde la masculinidad beta se resignifica como la estrategia necesaria para sobrevivir en un mundo invadido por el feminismo. Con esto, se conforma una retórica híbrida, pues a partir de metáforas y mitologías tradicionales se configuran narrativas que suman cuestiones como las flexiones de género tanto en las prácticas de los hombres como en la sexualidad y la pornografía (Nagle, 2015; Ging, 2019), destacándose la "curiosidad bisexual" (Nagle, 2015) como factor que marca distancia con las mujeres y que refuerza los lazos entre varones. Zizi Papacharissi, en la línea de la feminista Sara Ahmed (2004), dimensiona estas narrativas con enorme carga afectiva observando cómo es que intervienen los avances de la tecnología digital en la conformación de estas "nuevas" posiciones subjetivas. Esto es gracias a las interacciones en las redes sociodigitales, la velocidad, el anonimato, la incidencia de algoritmos y el desmembramiento social (tradicional) (Papacharissi, 2014: 17).

La noción de "masculinidad híbrida" es otra de las instancias teóricas que ha servido para explicar las inherentes contradicciones a estas expresiones subjetivas, sobre todo si se piensan a la luz de los valores tradicionales que la llamada masculinidad hegemónica determina como elementos de configuración de la dominación. Esta categoría permite pensar cómo es que se relacionan estos sujetos virtuales con la vida offline. Así, mientras que autores como Eric Anderson $(2008 ; 2009)$ vieron en la inclusividad un paso hacia una masculinidad menos rígida y violenta, ya que la homofobia parecía diluirse en pos de varones emocionalmente más expresivos, Tristan Bridges y C.J. Pascoe observan una estrategia para que algunos hombres mantengan su estatus social, político y económico. Esto lo hacen expresando formas aparentemente más blandas y gentiles (Bridges y Pascoe, 2014), muchas tomadas de las masculinidades gay, así como conformando jerarquías de alianza masculina menos notorias. Además, ignorando las estructuras vigentes de violencia. En todo caso, bajo el mantenimiento de avatares digitales en los que dan rienda suelta a sus emociones y fantasías antifeministas, como se ha dicho.

Hay otras contradicciones que subyacen en las posiciones masculinistas, por ejemplo en los espacios de interacción digital en los que participan estudiantes universitarios mexicanos. Un ejemplo lo constituyen las referencias a que los "compañeros gay" también son hombres — y por tanto igualmente sufren los efectos negativos del feminismo-, aunque en los comentarios posteriores esto sea motivo de burla o rechazo. Otra paradoja aparece en aquellos usuarios que expresan un sexismo cauteloso, basado en discursos con apariencia científica, siendo que en las interacciones con otros participantes el tono va subiendo. Con esto van cruzando límites, llegando a expresiones de violencia sexual contra las mujeres, así como homófoba, en niveles altos. En esta línea, trabajos que observan el comportamiento de la masculinidad beta identifican posiciones dobles, como cuando se ofrecen estrategias para pasar desapercibidos — como masculinistas_ en la vida real (Kaufman, 2015; Zapata 2020).

De acuerdo con R. W. Connell y James Messerschmid, los ejemplos anteriores igualmente operan desde la conocida masculinidad hegemónica, pues bajo esta tanto pueden repudiarse como incorporase elementos de manera selectiva (2005: 848). Es así que la masculinidad geek retoma aspectos de la hipermasculinidad, como el dar más valor a lo intelectual que a lo emocional, mientras que otros los rechaza, como el valorar en extremo a la potencia sexual y deportiva (Kendall en Ging, 2019: 642). Esto tiene que ver con el hecho de que se autoperciben como sujetos marginales, pues al ubicarse en esta posición se presentan como incapaces de reconocer sus privilegios, aunque solo se trate de estrategia retórica, nada más. Muchos de los memes que producen e intercambian dan cuenta de esta doble moral, basada en tropos, siendo desde esta suerte de juego de representación que refuerzan los límites sexistas, algunos de estos aparentemente superados en los campos de la vida social tradicional. 
Un ejemplo más lo constituye el discurso según el cual en las universidades se habla de igualdad, insistiéndose en cómo desde políticas y programas se han abolido las inequidades más aparentes. Así, se hace explícito el ascenso de las mujeres, el gran número que ha alcanzado puestos altos, o todos esos lugares de la universidad en las que ellas son mayoría, aunque sin perspectiva crítica de género, lo que demostraría que para ellas sigue siendo más complicado, pues necesitan más tiempo, energía, jornadas de trabajo y renuncias. Lo interesante es que este mismo tropo constituye una de las bases retóricas en las que se funda el masculinismo digital, ya que es leído como parámetro para manifestar la pérdida de espacios por parte de los varones. Con esto, un mismo sujeto puede situarse en la igualdad políticamente correcta offline, y en el sexismo más férreo en la manosfera online.

La manosfera es un conglomerado de diversas prácticas de masculinidad, muchas de estas contradictorias, por lo que se resiste a ser leída bajo las formas con las que los estudios de la masculinidad han mirado a las formas tradicionales en las relaciones educativas. A su carácter transnacional se suma el anonimato, o en su defecto, la interacción mediada — no "cara a cara" —, lo que hace aflorar ideas y posiciones altamente violentas. De hecho, como Ging destaca a partir de una serie de estudios sobre violencia digital, esta interacción facilita performances hostiles e ilegales de masculinidad, pues las estrategias de intimidación no solo se textualizan, como en el meme, sino que se multiplican. ${ }^{19}$

\section{Dispositivos de sexismo digital: los memes}

¿Qué pasa, entonces, en un mundo virtual en el que las subjetividades masculinas se reorganizan, obscureciéndose las identidades reconocibles, el cuerpo y la procedencia étnica y social (Ging, 2019: 643)? ¿Y mediante qué recursos digitales se generan empatías capaces de unir a esos varones de procedencias, intereses, hablas e historias de vida no ya solo diversas, sino incluso antagónicas? Como Papacharissi arguye, internet promueve asociaciones afectivas y emocionales de empatía, mucho más que la asociación o interrelación a partir de valores o principios políticos, de acuerdo con las normas de la vida real (2014: 23). Este poder afectivo, retomado por la masculinidad como un bastión para sobrevivir a los embates del feminismo, opera en gran medida bajo la efectividad y el poder comprobados por lo que L. Shifman llama la "meme-based communication" (2013).

El meme masculinista se propone, así, como una tecnología de género ${ }^{20}$ privilegiada para hacer converger, por una parte, a las estrategias retóricas mayores — como la victimización de los hombres-, desde donde se armonizan las inquietudes, incomodidades y afrentas antifeministas, que son el criterio de base. Por otra, funcionan como un catálogo de los ejes temáticos con los que se orquesta el masculinismo digital. Esto es, una mezcla de los supuestos derechos de los hombres (inequidad en matrimonio, paternidad, sexualidad); los temas esenciales mediante los cuales la misoginia tradicional ha soportado al orden de género (como la administración del aborto); una dedicada atención al problema de la violencia de género sufrida por ellos, en donde se alude a que ellos mueren más - y se suicidan en mayor número-, etc. Todo esto ignorando cualquier perspectiva de género. A esto se suman las

\footnotetext{
${ }^{19}$ Ging, a la hora de identificar expresiones y tácticas que orbitan en la manosfera, refiere al uso de "dick pics" en interacciones online, públicas o privadas, en las redes sociodigitales, así como en las aplicaciones para ligar. Esta acción involucra, en un grado alto, a las relaciones con compañeras universitarias (2019: 643). Esto se lee como una forma de sexualización que puede llegar a citar a la cultura de violación. En todo caso, la hipersexualización masculina es una conocida táctica para la sumisión femenina.

${ }^{20}$ De acuerdo con Teresa de Lauretis, la tecnología de género implica a las técnicas y estrategias discursivas mediante las cuales es construido el género. Incluye tecnologías amplias, como el cine, y discursos institucionales, como las teorías, con el poder para dominar el campo de significación social, produciendo, implantando y promoviendo representaciones de género (de Lauretis, 1989). En el caso del meme masculinista, estas representaciones apuntan a una visión de mundo doble: la de un patriarcado "tradicional" y la de un posible régimen feminista implantado.
} 
denuncias en cuanto a que el feminismo estaría diciendo demasiado y contando con una enorme cantidad de canales. A grandes rasgos, estos son los núcleos de sentido de tal activismo.

Como subgénero emocional, el meme se puede situar en lo que Demetrakis Demetriou denomina un "pragmatismo dialéctico" (2001: 345); es decir, un lugar de expresión eficaz desde el que la retórica de victimización de los varones obtiene una enorme carga afectiva; un plus de emociones. El meme se presenta como un dispositivo altamente capaz de sintetizar los sentimientos de grupos heterogéneos, amplificándolos de manera estratégica. Con esto, bajo la apariencia inocua y nada solemne de género popular y menor, se cumplen dos objetivos: establecer un frente de resistencia contrafeminista, además de cuestionar y erosionar los avances y discursos que amenazan poderes y privilegios. En esta deriva, la noción pragmática y dialéctica de Demetriou se presenta como un proceso de apropiación en el que la clase fundamental está en constante interacción dialéctica mutua con grupos aliados, apropiándose de aquello que le resulte discursivamente rentable para el proyecto de dominación en un momento histórico particular. Los elementos pragmáticamente inútiles o dañinos, en cambio, son subordinados y eliminados porque no tienen valor histórico (2001: 345). Esto demuestra cómo en esta fase de la masculinidad sexista los viejos objetivos permanecen, aunque las subjetividades cambien, transiten y crucen límites antes impensables: como el de la homofobia. Se refuerza, en todo caso, otra clave esencial para la operatividad: la asociación entre pares masculinos. Esto se profundiza en el análisis de uno de los memes.

Como Demetriou agrega, la finalidad de estos procesos de masculinidad es crear una amalgama, una suerte de equilibrio que se apropia de las mejores estrategias externas a la hegemonía (2001: 345346). Estas estrategias no solo apuntan a la toma de prácticas e ideales de aquellas que Connell denominó "masculinidades subordinadas", o la relajación ante limitantes aparentemente esenciales — como se acaba de expresar-, sino a la incorporación de dispositivos de comunicación efectiva, como el meme en la época de la universidad digital. Este, como ya lo hicieran los géneros mayores en la deriva de la humanidad — la literatura, el cine_-, o incluso los géneros culturales menores o populares — la historieta, la caricatura-, se suma a los artefactos de comunicación cotidianos más efectivos a la hora de reforzar y desambiguar, paradójicamente, los fenómenos, miedos y problemas del mundo, en un lado; pero también los deseos, fuerzas y poderes, como los de la dominación masculina. El chiste es un recurso retórico que siempre ha mostrado esos dos lados en las interacciones humanas. El meme trabaja de manera similar en las nuevas mediaciones, las cuales explosionan durante la vida en línea y el confinamiento pandémico. Bajo esta lectura, si la universidad es orillada a un toque de queda digital, en ese extremo de la vida afloran los dispositivos de interacción que a la vez la explican y administran.

Si el meme es eficaz por su doble condición dialéctica y pragmática — como lo es la esencia misma de la masculinidad-, esto lo convierte tanto en un arma pro como antifeminista. Como pariente digital del chiste, del dicho y del refrán, de acuerdo con esa posibilidad de unir tradición con visión de mundo, entonces su efectividad radica en su capacidad retórica. La retórica, como disciplina discursiva, es una instancia que mira a la eficacia comunicativa en términos persuasivos; es decir, en cuanto a qué tan efectivo resulta un discurso - una suma de tropos - a la hora de convencer. Otra forma de decirlo es: a la hora de imponer una idea del mundo, un sistema de reglas, una autoridad. ${ }^{21}$ En este sentido, la intención comunicativa del meme se une a la de esas grandes retóricas legales, epistémicas, históricas o judiciales; todas provenientes de instituciones históricamente masculinas. El meme, como el chiste, se clasifica por subgéneros: de curas, de políticos, de negros, de maricones, de mujeres, de putas, etc. En el orden digital de género vigente, el del confinamiento, es o feminista o masculinista. En esta dialéctica no hay espacio para los grises, ¿pues existe el chiste sexualmente degradante para la mujer, por ejemplo, que al mismo

21 Para Manuel Asensi, los textos retóricos, de mayor o menor complejidad —el cine, la literatura, un anuncio...— tienen la capacidad de modelizar a los sujetos; de incidir en su visión de mundo. Esto lo logran, de hecho, de acuerdo con su capacidad para sumar conceptos con afectos, incitando a sus receptores para actuar de tal o cual manera (Asensi, 2011). 
tiempo no sea misógino, sexista o violento? Hay grados de violencia simbólica, sin duda, pero estos no parecen estar tan claros a la hora de la misoginia virtual.

\section{Retóricas masculinistas en cuatro memes}

Los memes que se analizan a continuación fueron publicados en el referido grupo de Facebook, "Masculinismo México". De acuerdo con la descripción del espacio virtual, este se conforma por varones estudiantes universitarios de México, aunque no se precisen adscripciones, se exhiban estadísticas ni se corrobore esta afirmación. La página cuenta con 23,791 seguidores y está ligada a la web https://linktr.ee/Masculinismo_MX_Oficial, a la cuenta de Twitter@MxMasculinismo y al perfil de Instagram@masculinismomxoficial.

La selección de los memes se realizó bajo un criterio basado en el contenido y su apunte a, por una parte, lo que en este trabajo hemos señalado como los ejes temáticos o núcleos de sentido fundamentales del masculinismo; asimismo, por su inclusión de temas y debates reconocibles de los estudios de la masculinidad y de los feministas. Finalmente, también se buscó un apunte claro a las nuevas construcciones de subjetividad masculina, basadas en la visión de mundo masculinista, así como un evidente tono de violencia en contra de las mujeres feministas. En todo caso, la selección resultó un tanto aleatoria y representativa, pues si bien se privilegiaron los memes más elaborados, sobre todo en términos retóricos y de tropos, incluso los más simples replican, en una u otra forma, a los elementos mencionados.

Como en todo meme, se desconoce la autoría, procedencia y fecha de confección. Todos fueron compartidos durante la pandemia, lapso en el que se observa un incremento de las publicaciones e interacciones en el grupo. Como se ha dicho, a esto se suma el activismo feminista, que en el caso de la UNAM alcanzó su punto más alto en la vida offline justo al inicio del confinamiento.

\section{Hombres domados}

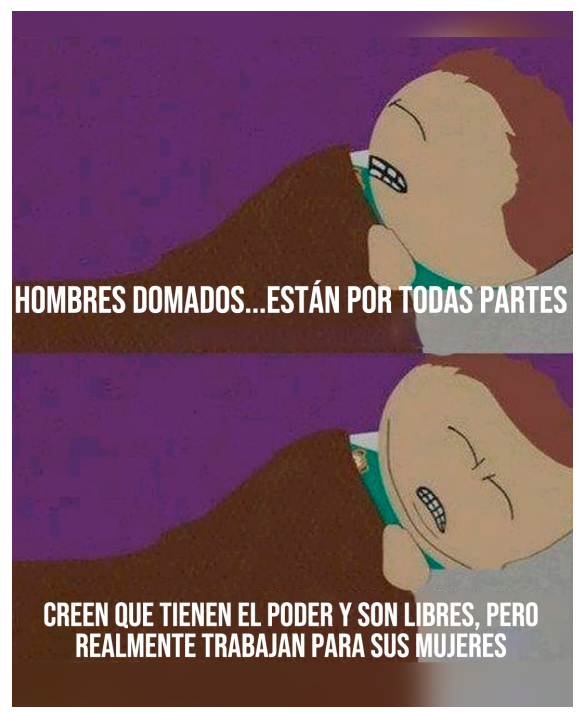

Fuente: "Masculinismo México".

En el meme que podemos nombrar "hombres domados" convergen buena parte de los elementos teóricos y experienciales hasta ahora expuestos. 
En primer lugar, este ejemplo evidencia una posición clara ante la tensión subjetiva actual de la masculinidad. El tropo del "hombre domado", ${ }^{22}$ como una clara parodia del varón profeminista —que en los ámbitos de comunicación y activismo sociodigital se nombra "varón aliado" o "deconstruido"-, por un lado asegura un lugar dentro de la manosfera como espacio de acogida de los afectos contrafeministas, ya que el circuito comunicacional del meme sitúa a quien lo publica, a quien lo lee - lo acepta mediante la risa- y lo replica. Como se sabe, el éxito de un meme radica no solo en su económica arquitectura, sino en su capacidad para ser "reposteado". De hecho, en la vida en pandemia hubo una aceleración de lo que se define como "hyperlinking", sobre todo en grupos organizados y radicales.

En segundo término, la posición "contra" aviva el interés de estos hombres por recuperar discursos conservadores que rebuscan en roles y estereotipos de género. Con esto, insisten en apuntar a la diferencia sexual como principio rector de la dominación masculina, ya que, al plantear un escenario polarizado, aceptan de pleno que es la diferencia sexo-género la base para ejercer el poder en las sociedades.

Ahora, las contradicciones que este dispositivo plantea surgen frente a algunos de los enunciados de base que, según los contrafeministas, permiten su reacción: la idea generalizada de que la igualdad de género ha alcanzado los espacios de la vida social, incluidas las relaciones en los hogares y en la universidad, por ejemplo. Esto se resume en la repetición de la idea: “¿de qué se quejan si ya hay igualdad en todos lados?". Lo curioso es que este enunciado es rápidamente puesto en tela juicio por sus propios detentores, al referirse a las molestias frente a una "batalla de los sexos" — un tropo básico del sexismoque, por lo menos en las IES, ellos creen estar perdiendo, como se ha expresado. El masculinismo digital es, con esto, una esfera plagada de lugares comunes.

En todo caso, la cuestión de la "batalla" como energía que sostiene al binomio sexogénerico y que cita al lado privilegiado de este como el lugar del poder —ese que los "hombres domados" creen tener, pero han perdido- de hecho comprueba todas las tesis feministas. Esto, los avatares digitales del masculinismo ni lo saben ni lo toman en cuenta. Sin ir más lejos, la cuestión del trabajo, de las relaciones de pareja y afecto como una serie de actividades productivas y jerárquicas, se suma a la órbita de la operatividad del orden de género como una instancia privilegiada de la economía y de las relaciones humanas cosificadas por la visión de un mundo capitalista y neoliberal. El "hombre domado" resulta ser un cuerpo-sujeto cosificado, que ahora ocuparía el (bajo) lugar de la mujer. Lo que este meme elude es ese proceso, señalado por Rita Segato (2006), mediante el cual el mandato de masculinidad trabaja provocando una natural predisposición de los sujetos para habituarse a la violencia y a estrategias de reificación. Es decir, un regular entrenamiento para convertir a las mujeres en cosas. El sentido profundo de este meme apunta, así, a un mundo de distopía masculina en el que la balanza se habría volteado. Este es otro de los tropos centrales a la ideología masculinista —ese "mundo al revés"—; sin embargo, como en todos sus sentidos de base, la cuestión es no razonarlos para sí.

En todo caso, como ente pandémico, se puede decir que el varón domesticado sufre en el silencio de su cama.

\footnotetext{
22 Podría pensarse en el "mandilón" mexicano como un antecedente del "hombre domado". Lo interesante es observar cómo el primero es un producto del patriarcado tradicional y el segundo un resultado directo del supuesto régimen opresivo feminista.
} 


\section{El seguidor "funado"}

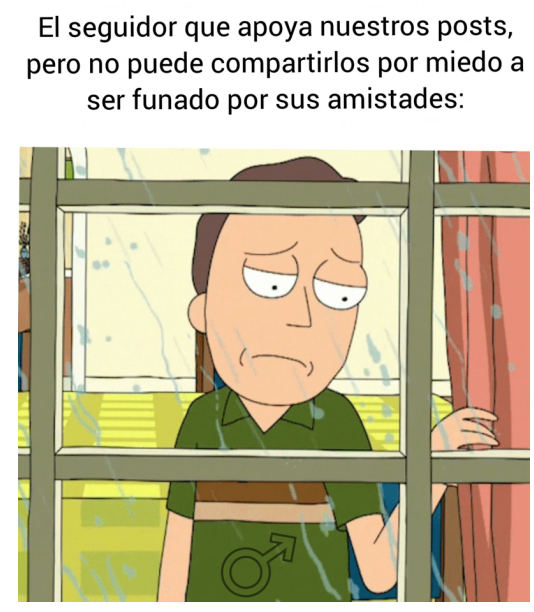

Fuente: "Masculinismo México".

Este meme, en una primera ojeada, parece bastante simple. En un nuevo régimen de terror instaurado por las feministas, el varón habría perdido el derecho a mostrar su "verdadero yo" social, cultural y "de creencias". Se trata, pues, de una cuestión de ideología; es decir, confundir lo artificial con lo natural, como sabemos gracias a Marx. El acometimiento de una distorsión de la realidad es lo que parece planear en el mensaje de este meme. El seguidor "que apoya" los posts de la manosfera y a los grupos masculinistas, pero que no es capaz de hacerlo público por temor - y por tanto vive confinado en una jaula, su hogar-, cumple al dedillo, como sujeto, con la definición dada por Althusser: "La ideología es una representación de la relación imaginaria de los individuos con sus condiciones reales de existencia" (1975: 144).

La contradicción sine qua non de la retórica masculinista aparece ahí en donde este meme demuestra algunas de las aseveraciones centrales del feminismo; es decir, que una serie de condiciones ideológicas, basadas en falsos universalismos y enunciados científicos cuestionables, como los de la psicología evolucionista, constituyen la esencia desde la cual trabaja el sistema de sexo/género. Este es, de acuerdo con Gayle Rubin, "[...] un conjunto de acuerdos por el cual la sociedad transforma la sexualidad biológica en productos de la actividad humana y en las cuales estas necesidades sexuales transformadas, son satisfechas" (1996: 37). En este caso, lo que falta, lo que se ve amenazado, es ese sistema de producción y satisfacción cuyo material son las mujeres.

El varón creyente de la manosfera, que no puede mostrarse como es, si bien se encuentra enjaulado dentro del mismo sistema, no es, ni mucho menos, una víctima. Aquí la estrategia vuelve a ser la misma; la del opresor ocupando el lugar del oprimido. Un recurso tan antiguo como la dialéctica de las clases sociales, basada en intereses y no en esencias. Asensi, al hablar de la identidad del subalterno, recuerda como

para [Marx] no existía nada parecido a una "esencia" o "instinto" de clase, sino una comunidad de intereses surgida del hecho de que un determinado grupo humano vive bajo unas mismas condiciones económicas, que les pueden llevar a una confrontación hostil. Es, por consiguiente, el interés el que le da lugar a la existencia de una clase social. (2011: 82)

Como se ha visto, la victimización es la estrategia retórica mayor del masculinismo. Para Demetriou, la finalidad de un dispositivo en la era de la interacción digital es apropiarse de las "mejores estrategias" externas a la hegemonía (345-346). Esta apropiación está fundada en intereses de una 
economía sexual, se puede agregar. Los tropos que fundan a los memes lo demuestran una y otra vez. Ging, por su parte, señala cómo estas estrategias, materializadas en los dispositivos que organizan a la manosfera, cumplen además con otra función: hacer que sus usuarios puedan ignorar las contradicciones inherentes a sus propios bienes y valores. Esto es, a las bases de su propia ideología, como se vio en el meme anterior.

Ahora bien, el término "funado" no es casual, ya que lleva a este meme al terreno de la tensión entre activismos. En la arena de la batalla sexual, los practicantes del masculinismo buscan su nicho en la red mediante los significantes de la afrenta. El verbo "funar", de acuerdo con el Diccionario de americanismos, en Chile nombra el "organizar actos públicos de denuncia contra organismos o personas relacionados con actos de represión delante de su sede o domicilio" (s/p). Tal como menciona el Departamento de Género y Equidad de la Universidad Tecnológica Metropolitana de Chile, el término se ha vuelto muy popular en el último año, 2020, en el confinamiento, en especial por el incremento de actividad en las redes sociales que derivan en denuncias públicas hacia otras personas, destacándose las de las violencias en la universidad (UTEM, 2020: s/p).

Al referir abiertamente al peligro del "escrache", y al situar al varón temeroso mirando al mundo desde la "jaula patriarcal" — su ventana_, se cita otra de las tropologías centrales para el activismo de misoginia virtual: el referido "free speech", como apunte a unos derechos (de los hombres) que estarían amenazados bajo el régimen feminista. La carga emocional de la imagen, así como la representación de este hombre —acongojado y frágil—, lo inscriben en esa condición dialéctica y pragmática que exige la masculinidad como energía para funcionar: la de un "macho sensible", un geek victimizado.

\section{La doble condición de marginación del hombre beta}

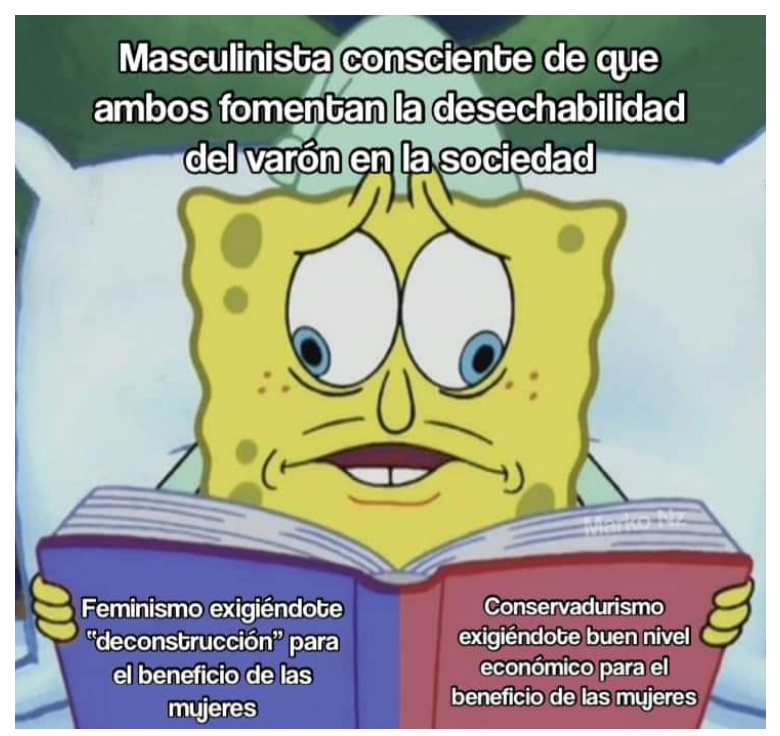

Fuente: "Masculinismo México".

Bob Esponja, aterrando, desvelado y viviendo una vigilia de miedo ante las dos opciones que la vida actual le presenta en el confinamiento — por la pandemia y el orden feminista—, ilustra, mediante la acertada elección del libro como fuente autorizada del saber — de la ley_, no solo la dicotomía con la que, se presume, el feminismo busca reducir a los varones, sino a esa "deconstrucción" obligatoria, que a quienes beneficia es a ellas. 
Aquí el mundo relacional vuelve a verse bajo la lógica del mercado, el cual se debe a un amo, el género rector; es decir, aquel que ocupa el lugar de dominio. En la disyuntiva que se le presenta a Esponja, en un lado aparece el conservadurismo, que bien puede leerse como un tiempo mítico y anterior a la irrupción de los feminismos. Un mundo en el que aquellos que mandaban eran los hombres, pero aquellos conocidos como alphas, según se ha visto en la retórica masculinista. Nuevamente en clave económica, solo los varones socialmente aceptados, tanto por su estatus como por su físico, tienen acceso al bien de los cuerpos de las mujeres. En esa amalgama sentimental, que la manosfera busca equilibrar (Demetriou, 2001), el tropo incel irrumpe, mostrando que no todo tiene que ver con los derechos en peligro de los hombres - la paternidad, el poder reconocerse como violentado, la crianza de sus hijos_-, sino más bien con sexo y con dinero. Con esto, no resulta tan curioso que los masculinistas marquen distancia con el ordenamiento de género anterior a los feminismos. Esta explicación nos la otorgan la teorización de la manosfera y el modelo de subjetividades masculinas que propone; un mundo de alphas y betas en el que la única oportunidad para los varones es renacer como zetas. ${ }^{23}$

Estudios de la masculinidad recientes, en un camino hacia la igualad y la justicia, han venido insistiendo en la imperiosa necesidad de que los hombres nombren y reconozcan los dividendos que el patriarcado les reporta (Fabbri, 2016; Azpiazu, 2017). Esto en la línea del señalamiento de que en verdad muchos hombres se han puesto la camiseta profeminista —o de la inclusividad — con tal de no realizar dicha tarea. En todo caso, parece que hay pocas instancias metodológicas que permitan e inciten a esta actividad, por ejemplo, en la educación y la universidad. En cambio, la pandemia y el confinamiento los han visibilizado velozmente. Basta apuntar, como se expresó en el inicio, a las dobles y triples jornadas de las mujeres por motivos de limpieza, cuidados y educación. Lo llamativo es que el masculinismo, no sin ironía, también trabaje hacia este objetivo. Sexo y dinero parecen ser el principio, la guía, para comenzar a clasificar los beneficios que el orden de género, incluso trastocado por la última gran ola feminista, aún reporta a muchos hombres.

Como parte de la vida en las células del hogar, a un Bob Esponja aterrado, la manosfera se le presenta como la única vía de escape.

\section{Varones vírgenes y consumidores de trabajadoras sexuales}

\section{COMO LAS EXPLICA EL MIEMBRO RADICAL DE LA COMUNIDAD:}

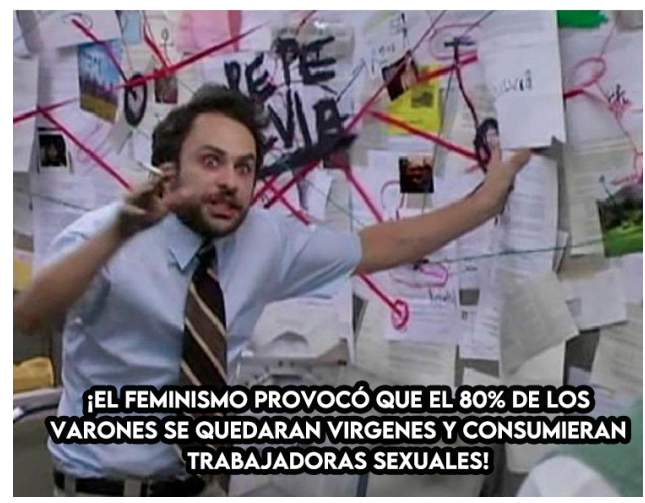

Fuente: "Masculinismo México".

\footnotetext{
${ }^{23} \mathrm{El}$ hombre zeta es un guerrero "sociosexual”. Es emergente y bruto. Lucha por encontrar su lugar, pero lo hace con la ayuda de otros que como él despiertan en la internet (Ging, 2019: 650).
} 
La subjetividad beta pide un tránsito hacia el sitio identitario de la liberación. Es en este sentido que se proponen como guerreros sociales, tanto frente a las mujeres como frente a los machos alpha. El "derecho agraviado", que Kimmel (2015) observa en la amalgama de la manosfera, implica un pliego petitorio que parece ir creciendo a la par que las interacciones digitales y el activismo feminista. En todo caso, el derecho al sexo y el libre acceso a los cuerpos de las mujeres resulta de primer orden para este.

Beatriz Ranea, en su reciente reflexión sobre el estado actual de la masculinidad, bajo la idea de "desarmarla", señala cómo es que se siguen replicando tres bases, que aquí se leen como límites sexistas. La primera es el terror a lo femenino — "no seas una niña" (2021: 35) —; la segunda es la heteronormatividad como medida del mundo y del propio hombre, que ante todo es sexual, pues exige reglas como una temprana y exacerbada potencia, así como la idea de que el varón es siempre "un animal en celo", un ente que necesita descargarse (2021: 43). La última es la constante búsqueda de alianza entre pares para hacer funcionar a la masculinidad, de acuerdo con las dos condiciones anteriores. Esto es lo que Ranea llama “uno de los nuestros” (45).

El meme en cuestión apunta no solo a las reglas digitales que se dictan desde la manosfera, sino a una versión offline y prepandémica de la vida, en la que los estudiantes, como practicantes de la masculinidad, replican estas tres condicionantes, aunque sea bajo nuevas identidades. Con esto, el miedo a ser una mujer, desde donde surge una idea de virilidad defendida por el sexismo tradicional, mira a esas viejas mitologías según las cuales la feminidad significa pasividad, sumisión, dependencia, debilidad, delicadeza..., mientras que lo masculino es activo, poderoso, independiente, autónomo, fuerte, racional, etc. (Ranea, 2021: 37). Estos tropos sexuales siguen dictando lo laboral, lo profesional y la organización de tareas en casa, para lo cual el confinamiento significó una amenaza para el orden establecido, sumados los avances feministas. La tropología, el cambio de posiciones de sentido, surge ahí en lo que estos hombres ven como una amenaza a su condición, pues básicamente se les sigue educando para disponer de las mujeres (Fabbri en Ranea, 2021: 37), pero la propia deriva de la masculinidad, paradójicamente, les ha convertido en machos de segunda. Antes se habló de los privilegios en la órbita del sexo y el dinero, siendo que ambos conceptos están relacionados con los cuerpos y la psique de las mujeres, de ahí la denuncia, de ahí la aseveración: "El feminismo provocó...".

El tropo de la potencia sexual del hombre como regla básica de su ser y proceder se hace explícito en esta afirmación. La lógica relacional del mundo está basada en la sexualidad masculina y en su inevitable necesidad eyaculatoria en cualquier cuerpo femenino, sea el de una mujer dominada (pues las liberadas se lo niegan) o el de una prostituta. La homosociabilidad, por su parte, como regla operativa y corporativa del mundo, aún tratándose de uno alternativo y virtual —el de los beta-, se exhibe como amenaza y recordatorio a las mujeres feministas: "Como las explica el miembro radical de la comunidad". Quien dice grupo dice clan, fratria, logia.

Es evidente la incoherencia de sentido que esta afirmación conlleva, pero acaso su estrategia retórica va en esa línea de la exageración y el despropósito. Esto porque más que combatir la batalla contra el feminismo con datos duros, lo que busca mostrarse es que: 1. los varones continúan considerando a las mujeres como seres secundarios y a su disposición; 2. Que la base de la masculinidad está en la potencia sexual — aunque no todos accedan a esta—; y 3. Que continúan asociados y agrupados, mostrándose además, muchos de ellos, radicalizados, de forma no muy distinta a los talibanes en Afganistán, si es que miramos a la esencia política de la masculinidad. 


\section{Conclusiones. La cara masculinista de la pandemia en la universidad digital}

P. B. Preciado, al denunciar la acelerada descorporeización dada por las fronteras digitales durante la pandemia; al señalar las máscaras semio-técnicas y cibernéticas, bien podría estar preguntado: ¿qué clase de aceleración en los discursos de la violencia simbólica de género desembocan en el contenido de memes como estos?

Una respuesta preliminar estaría en esa carga afectiva que manifiestan los dispositivos — los memes_- desde los que se configuran esas nuevas formas de ser hombre, entre la queja, la incomodidad y la búsqueda por refrendar algunas convenientes bases de la masculinidad. Para ello dependen de la velocidad de las interacciones, así como del desmembramiento social y la confrontación que permiten. Otra pregunta iría en la línea de pensar cuál es la penetración que estas posiciones subjetivas tienen en la vida offline. ¿Cuáles son sus efectos "reales" (de violencia) en vidas y cuerpos?

Las retóricas masculinistas, que alcanzan en el meme una expresión destacada y "útil", exponen las emociones que enlazan a ese grupo variopinto de varones que se creen empujados al margen; un espacio, real o virtual, al que saben que no pertenecen. El uso de la violencia verbal se exhibe como una potencia que recupera a los viejos tropos misóginos y sexistas. La hibridez, sin embargo, y de manera irónica, les permite incorporar formas menos férreas, que de hecho los distinguen del hombre exitoso, socialmente aceptado y sexualmente deseado. Un último meme ilustra esta problemática, marcando incluso un quiebre más frente a una noción de masculinidad concebida como una unidad jerárquica cohesionada.

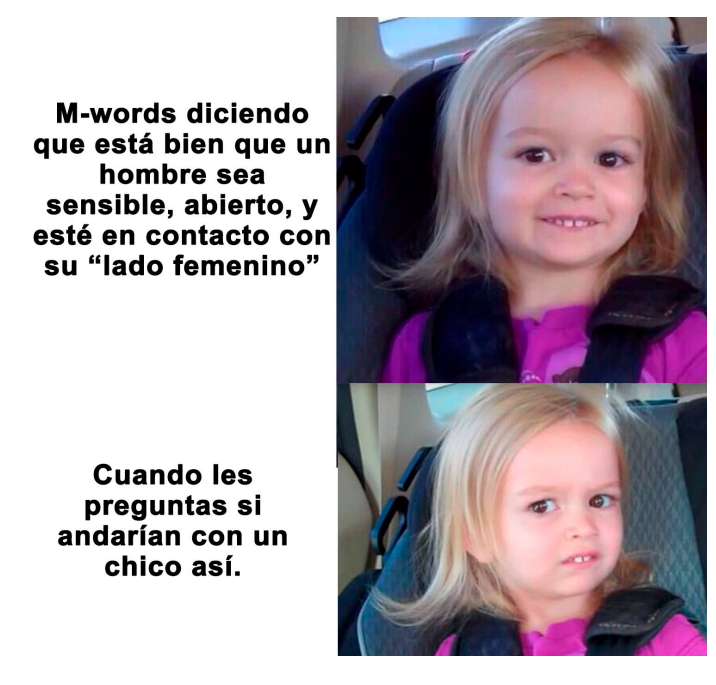

Fuente: "Masculinismo México".

La base, una vez más, vuelve a citar viejas mitologías, como la idea de que las mujeres a quienes buscan para relacionarse es a los "hombres más hombres", de acuerdo con la propia tradición masculina. Scott Kaufman expresa: "There are a lot of false dichotomies out there - left brain vs. right brain, nature vs. nurture, etc. But one really persistent myth, that is literally costing human lives, is the distinction between 'alpha' and 'beta' males" (2015: s/p). El viejo tropo sexista se renueva como figura retórica masculinista: las mujeres buscan a hombres alpha para el sexo y el matrimonio; a los beta recurren para explotarlos laboral o financieramente (Ging, 2019: 650). Por ello, los que no han tomado la "pastilla roja" han sido secuestrados por el "gynocentric establishment" (2019: 650).

Como estrategia, los beta se presentan como capaces de incorporar formas de feminidad — como la sensibilidad o la apertura emocional-; es decir, como disidentes de la hegemonía masculina, pero manteniendo las formas esenciales de su violencia. Al apuntar a las "M-words diciendo..." —las motherfuckers - , lo que hacen es mostrar ese doble espacio en el que habitan: el de la victimización y la 
misoginia extrema. Como Papacharissi arguye, la rabia es la emoción destacada; es el factor clave en la coalescencia política de los públicos conectados en la red digital (2014: 22). De ahí la propuesta de los hombres zeta: un guerrero; un varón emergente, sin pulir. Un sujeto que mira a la supremacía y al radicalismo desde su propio mundo en construcción: la manosfera.

Como se ha visto, en México algunas de estas intenciones están calando en las configuraciones y prácticas de subjetividad de estudiantes hombres. Finalmente, la manosfera es un sistema discursivo que se construye, a su vez, mediante redes que miran hacia un mismo espacio desde lugares que antes eran despreciados o ignorados — como los de los terceros y cuartos mundos-. Esto lo hace para mantener el poder mediante una estrategia ideológica (Ging, 2019: 653).

El confinamiento y la suspensión de la vida refrendaron las violencias al interior de los hogares. Así también, el aumento en las interacciones multiplicó las expresiones de ciberviolencia antifeminista, bajo un movimiento tropológico, aterrizado en recursos como el meme. En este impase, una de las claves para entender qué es aquello que permite la creación y circulación de materiales con tal contenido sexista, radica, por una parte, en el hecho de que las nuevas masculinidades al uso, lo que están asegurándose es modos de pertenencia — su membresía — a un hogar virtual; además de la posibilidad de ser un hombre bajo nuevas reglas, aunque también bajo los lineamientos de una ideología de soporte; de una serie de creencias capaces de operar mediante mitos, ficciones y una retórica propia.

Ahora, como en toda retórica que parte de un guion en extremo masculino, radical y totalitario, un claro enemigo es necesario. En este caso es el feminismo. Con esto, de paso, se siguen asegurando los beneficios naturalmente otorgados a los cuerpos con pene que seguimos llamando "hombres".

\section{Bibliografía}

AHMED, Sara (2004), The Cultural Politics of Emotion. Edinburgh, Edinburgh University Press.

ALCOCER, Jenifer (2020), "Se registran 103 feminicidios durante cuarentena por covid-19”. Consultado en $<$ https://www.publimetro.com.mx/mx/no-ticias/2020/04/13/se-registran-103-feminicidios-cuarentena-covid-19.html> (4/08/2021).

AltHusser, Louis (1974), Escritos. Barcelona, Laia.

ANDERSON, Eric (2009), Inclusive Masculinity. The Changing Nature of Masculinities. New York, Routledge.

ASENSI, Manuel (2011), Crítica y sabotaje. Barcelona, Anthropos.

AZPIAZU, Jokin (2017), Masculinidades y feminismo. Barcelona, Virus.

BRIDGES, Tristan y C. J PASCOE (2014), "Hybrid Masculinities: New Directions in the Sociology of Men and Masculinities", Sociology Compass, vol. 8, n. 3, pp. 246-258. DOI: <https://doi.org/10.1111/soc4.12134>.

BUQUET, Ana (2011), “Transversalización de la perspectiva de género en la educación superior. Problemas conceptuales y prácticos", Perfiles Educativos, vol. 33, pp. 211-225.

BUTLER, Judith (2020), “El capitalismo tiene sus límites”, en Agamben, Giorgio; Zizek, Slavoj; y A.N. (coords.) Sopa de Wuhan. Pensamiento contemporáneo en tiempos de pandemias. Editorial ASPO (Aislamiento Social Preventivo y Obligatorio).

CERva, Daniela (2020), "Activismo feminista en las universidades mexicanas: la impronta política de las colectivas de estudiantes ante la violencia contra las mujeres", Revista De La Educación Superior, vol. 49, n. ${ }^{\circ}$ 194, pp. 135-155. DOI: <http://resu.anuies.mx/ojs/index.php/resu/article/view/1128>. 
ConNELl, Bob y James Messerschmidt (2005), "Hegemonic Masculinity: Rethinking the Concept", Gender and Society, vol. 19, n. ${ }^{\circ}$ 6, pp. 829-859. DOI: <https://doi.org/10.1177\%2F0891243205278639>.

COPRED (2020), "Informe.Impactos diferenciados por COVID-19: diálogos con organizaciones de la sociedad civil". Consultado en <https://copred.cdmx.gob.mx/storage/app/media/informeimpactos-diferenciados-por-covid19-dialogos-con-organizaciones-de-la-sociedad-civil.pdf> (8/08/2021).

DE LAURETIS, Teresa (1989), "La tecnología del género", Traducción de Ana María Bach y Margarita Roulet, Tomado de Technologies of Gender. Essays on Theory, Film and Fiction. London, Macmillan Press, pp. 1-30. Consultado en <http://blogs.fad.unam.mx/asignatura/adriana_raggi/wp-content/uploads/2013/12/teconologias-delgenero-teresa-de-lauretis.pdf $>$ (8/08/2021).

Demetriou, Demetrakis Z. (2001) "Connell's Concept of Hegemonic Masculinity: A Critique", Theory and Society, vol.30, n. ${ }^{\circ}$, pp. 337-361. DOI: <http://www.jstor.org/stable/657965>.

DiCCIONARIO DE AMERICANISMOS (s/f.), "Funar", Real Academia Española. Consultado en <https://www.rae.es/observatorio-de-palabras/funar> (16/08/2021).

Diccionario De la Lengua Española (s/f.), "Tropología", Real Academia Española. Consultado en $<$ https://dle.rae.es/tropolog\%C3\%ADa> (16/08/2021).

FABBRI, Luciano (2016), "Colectivos de hombres y feminismos. Aportes, tensiones y desafíos desde (y para) la praxis", Sexualidad, Salud y Sociedad (Río de Janeiro), n. ${ }^{\circ}$ 22, pp. 355-368. DOI: < https://doi.org/10.1590/1984-6487.sess.2016.22.16.a>.

Ferrero, Clara (2017), “Vocabulario feminista que ya todos deberíamos dominar en 2017”. Consultado en $<$ https://smoda.elpais.com/feminismo/vocabulario-feminista-que-ya-todos-deberiamos-dominaren-2017/> (10/07/2021).

FINCHER, David (dir.) (1999), The Fight Club [película]. EUA, Fox 2000 Pictures, et. al.

GALVÁN, Melissa (2020), "Otra contingencia: la violencia contra las mujeres va en aumento". Consultado en $<$ https://politica.expansion.mx/mexico/2020/04/05/otra-contingencia-la-violencia-contra-las-mujeres-va-en-aumento> (12/08/2021).

GING, Debbie (2019), "Alphas, Betas, and Incels: Theorizing the Masculinities of the Manosphere”, Men and Masculinities, vol. 22, n. ${ }^{\circ}$ 4, pp. 638-657. DOI: <https://doi.org/10.1177\%2F1097184X17706401>.

Haywood, Chris y Mairtin Mac An GHAILl (2013), Education and Masculinities. Social, Cultural and Global Transformations. Nueva York, Routledge.

HEATH, Ryan y Renuka RAYASAM (2020), "Covid's war on women". Consultado en $<$ https://www.politico.com/newsletters/politico-nightly-coronavirus-specialedition/2020/04/29/covids-war-on-women-489076> (16/08/2021).

KAUfMAN, Scott B. (2015), "The Myth of the Alpha Male". Consultado en <https://greatergood.berkeley.edu/article/item/the_myth_of_the_alpha_male> (23/09/2021).

KIMMEL, Michael (2015), Angry White Men: American Masculinity at the End of an Era. New York, Nation Books.

LóPEZ, María Pía (2020), “La vida en cuestión”, en Svampa, Maristella; Cragnolini, Mónica; y A. N. (coords.), La fiebre. Editorial ASPO (Aislamiento Social Preventivo y Obligatorio).

MASCULINISMO MÉXICO, Facebook. Consultado en <https://m.facebook.com/MasculinismoMexicoOficial> $(16 / 08 / 2021)$.

MESSNER, Michael (2016), "Forks in the Road of Men's Gender Politics: Men's Rights vs Feminist Allies", International Journal for Crime, Justice and Social Democracy, vol. 5, n. ${ }^{\circ}$ 2, pp. 6-20. DOI: <https://doi.org/10.5204/ijcjsd.v5i2.301>. 
Mingo, Araceli (2020), "El tránsito de las estudiantes universitarias hacia el feminismo", Perfiles Educativos, vol. 42, n. ${ }^{\circ}$ 167, pp. 10-30. DOI: <https://doi.org/10.22201/iisue.24486167e.2019.167.59063>.

Mingo, Araceli y Hortensia Moreno (2015), "El ocioso intento de tapar el sol con un dedo: violencia de género en la universidad", Perfiles Educativos, vol. 37, n. ${ }^{\circ}$ 148, pp. 138-155. DOI: $<$ https://doi.org/10.22201/iisue.24486167e.2015.148.49318>.

Mingo, Araceli y Hortensia Moreno (2019), "Temor, desprecio y deseo como figuras del sexismo en la universidad”, Nómadas, n. ${ }^{\circ}$ 51, pp. 13-29. DOI: <https://dx.doi.org/10.30578/nomadas.n51a1>.

NAGLE, Angela (2015), An investigation into contemporary online anti-feminist movements. Tesis doctoral, School of Communications, DUC, Dublin. Consultado en <http://doras.dcu.ie/22385/3/Angela_Nagle_PhD_thesis.pdf> (23/10/2021).

Papacharissi, Zizi (2014), Affective Publics: Sentiment, Tecbnology, and Politics. Oxford, UK, Oxford University Press.

Preciado, Paul B. (2020), “Aprendiendo del virus”, en Agamben, Giorgio; Zizek, Slavoj; y A.N. (coords.), Sopa de Wuban. Pensamiento contemporáneo en tiempos de pandemias- Editorial ASPO (Aislamiento Social Preventivo y Obligatorio).

RANEA, Beatriz (2021), Desarmar la masculinidad. Madrid, Catarata.

RUBIN, Gayle (1996), "El tráfico de mujeres: notas sobre la `economía política'del sexo", en Marta Lamas (comp.), El género. La construcción cultural de la diferencia sexual. Ciudad de México, PUEG-UNAM, pp. 3596.

RuiZ-NAVARro, Catalina (2016), “\#MiPrimerAcoso: la historia detrás del Trending Topic”. Consultado en <https://www.vice.com/es/article/bned78/miprimeracoso-la-historia-detras-del-trending-topic> $(22 / 12 / 2021)$.

SEgATO, Rita (2016), La guerra contra las mujeres. Madrid, Traficantes de Sueños.

SHIFMAN, Limor (2013), Memes in Digital Culture. Cambridge, MA, The MIT Press.

TENA, Olivia (2010), “Estudiar las masculinidades ¿para qué?”, en Blázquez, Norma; Ríos, Maribel y Fátima Flores (eds.), La investigación feminista: epistemología, metodología y representaciones sociales. Ciudad de México, CEIICH-UNAM.

TOCHE, Nelly (2020), “Aumenta el ciberacoso durante el confinamiento". Consultado en $<$ https://www.eleconomista.com.mx/arteseideas/Aumenta-el-ciberacoso-durante-el-confinamiento20200512-0140.html> (03/08/2021).

UNOTV (2020), "Por “chistes machistas y misóginos" exhiben a profesor de la UNAM en video". Consultado en $\quad<$ https://www.unotv.com/nacional/profesor-de-la-unam-lanza-comentarios-machistas-esexhibido-en-video/> (20/06/2021).

UTEM (2020), "Qué es una funa y cuáles son sus consecuencias", en Noticias UTEM, UTEM. Consultado en <https://noticias.utem.cl/2020/01/08/que-es-una-funa-y-cuales-son-sus-consecuencias/> (03/08/2021).

VELA, Estefanía y Erika SMITH (2016), “La violencia de género en México y las tecnologías de la información”, en Internet en México. Derechos humanos en el entorno digital. Santiago de Chile, Derechos Digitales, pp. 57117.

VELÁZQUeZ REYES, Luz María; REYES JAIMES, Gabriel Renato y Laura ESPINOZA ÁvILA (2021), "De la ciberviolencia a la violencia física: el día que Holk irrumpió en la prepa”, Revista Educación, vol. 45, n. ${ }^{\circ}$, pp. 1-15. DOI: < https://doi.org/10.15517/revedu.v45i1.40529>. 
WACHOWSKI, Lilly y Lana WACHOWSKI (dirs.) (1999), The Matrix [película]. Village Roadshow Pictures by Silver Pictures.

ZAPATA, Raquel (2020), “Nuevas masculinidades', un concepto y un proceso marcado por el desconocimiento". Consultado en <https://amecopress.net/Nuevas-masculinidades-un-concepto-yun-proceso-marcado-por-el-desconocimiento $>$ (23/10/2021). 